\title{
Assessment of the Microbiome Collected from the Reproductive Tracts of Women from Saudi Arabia and Its Potential Influence on Infertility
}

\author{
A. Al-Rezaki ${ }^{1}$, W. Aldahmash ${ }^{1}$, S. Alwassel ${ }^{*}$, Z. Abotalib ${ }^{2}$ \\ ${ }^{1}$ College of Science, King Saud University, Riyadh, Saudi Arabia \\ ${ }^{2}$ Obstetrics and Gynecology, College of Medicine, King Saud University, Riyadh, Saudi Arabia \\ Email: *salwassel@ksu.edu.sa
}

How to cite this paper: Al-Rezaki, A., Aldahmash, W., Alwassel, S. and Abotalib, Z. (2017) Assessment of the Microbiome Collected from the Reproductive Tracts of Women from Saudi Arabia and Its Potential Influence on Infertility. Advances in Reproductive Sciences, 5, 23-32. https://doi.org/10.4236/arsci.2017.52003

Received: March 23, 2017

Accepted: May 19, 2017

Published: May 22, 2017

Copyright $\odot 2017$ by authors and Scientific Research Publishing Inc. This work is licensed under the Creative Commons Attribution International License (CC BY 4.0).

http://creativecommons.org/licenses/by/4.0/

\begin{abstract}
Background and Objective: Female infertility may be attributed to several causes that are fundamentally related to the health status of women. The main objective of this project was to correlate the abundance of the microbiota in cervicovaginal fluid to infertility. Materials \& Methods: A total of 36 married women who voluntarily came to the hospital in Riyadh for a routine visit participated in the study. To collect the cervicovaginal liquid, a Softcup ${ }^{\text {th }}$ menstrual device was used by the participant; the cup was then transported in a liquid nitrogen box to the laboratory for analysis. Results: The mean vaginal $\mathrm{pH}$ in normal women and infertile women was 3.96 and 5.06, respectively, and the difference between the two cohorts was significant $(p<0.0001)$. The results showed a clear correlation between the $\mathrm{pH}$ value and the floral species detected in the cervicovaginal liquid. In fact, normal flora is primarily composed of a heterogeneous group of Lactobacillus species that have been detected at $\mathrm{pH}$ range $3.0-4.5$, whereas a second group of bacteria mainly composed of Gardnerella vaginalis, Peptostreptococcus anaerobius and L. iners has been detected in a $\mathrm{pH}$ range between 4.5 and 5.5. The third group, with a $\mathrm{pH}$ range $>5.5$, is primarily composed of $G$. vaginalis, $P$. anaerobius, Mycoplasma hominis, Mobiluncus species and Atopobium vaginae. The protein content and viscosity of the cervicovaginal liquid were significantly lower in infertile women compared to normal women $(p<0.05)$.
\end{abstract}

\section{Keywords}

Female Infertility, Microbiota, Cervicovaginal Fluid, $\mathrm{pH}$, Viscosity 


\section{Introduction}

The World Health Organization estimates that approximately $8 \%$ of couples, or 50 - 80 million people worldwide, have some forms of infertility [1]. In industrialized countries, $10 \%-15 \%$ of married couples have had either primary or secondary infertility experiences [2]. This finding may be due to several causes that are fundamentally related to the healthy state of women. Some environmental factors such as smoking and alcohol consumption were linked to infertility. In addition, the exposure to some reproductive toxicants including lead and zinc was also correlated to infertility [2]. The microbiota composition of the reproductive organs is one of the multiple factors that modulate animal reproduction and may also affect embryonic development.

The human microbiota is found various organs including the skin, mouth, gut and vagina. This microbiota plays a crucial role in the health/disease status in both man and women. While the gut is populated with more than 800 microbial species, the vaginal tract hosts approximately only 50 [3]. Vaginal microbiota (VMB) are mainly dominated by Lactobacilli (particularly Lactobacillus iners, $L$. crispatus, $L$. jensenii and $L$. gasseri), which are associated with a healthy state in childbearing women [4]. Previous studies have reported the prevalence of at least six types of VMB that have been denoted as community state types (CSTs) [5] [6]. The VMB play key protective roles by maintaining low vaginal $\mathrm{pH}$ levels $(<4.5)$ through the production of lactic acid [7] [8] and antimicrobial compounds, or through competitive exclusion of non-indigenous pathogens [9] [10].

It is important to study the microbial communities in the reproductive organs of women within fertility risk and compare them to those in normal women. Such study will be able to determine whether or not the presence of some genera is significantly different between the two cohorts. While most of the bacteria found in the female reproductive organs are considered beneficial, some are considered as pathogens. Thus, the variation in bacterial communities between fertile and infertile women could be associated with level of infertility.

\section{Material and Methods}

\subsection{Data Collection}

The study was approved by the Research Ethics Committee in King Saud University. The study has been conducted on married women who voluntarily came to the hospital for a routine visit on a random day of their cycle. The subjects were assigned into two groups according to the level of their fertility. The first group includes married non-pregnant women who have been pregnant at least one time since mirage but without clinical intervention (control, $n=22$ ). The second group (Infertile group, $n=14$ ) includes women who were married to normal men but were unable to get pregnant after at least one year of marriage. These women are defined as infertile according to WHO. The sampling criteria for the infertile group were: at least one year of marriage without successful fertilization, more than 10 times intercourses per month, have no antibiotics and 
have not used any vaginal medication in the last two months. Twenty five women with risk of fertility were recorded, however only 14 have matched the inclusion/exclusion criteria.

At admission, clinical measurements and health history were obtained. These include age, weight, height, date of marriage and number intercourse. Subjects were asked to provide information about any medications they used in the last two months. Women from both groups were asked to obtain a self-sample of the cervicovaginal liquid at admission using Softcup ${ }^{\mathrm{Tm}}$ menstrual device (Evofem Inc., San Diego, CA, USA). A leaflet of clear instructions was provided to all subjects. Briefly, the Softcup was inserted by the participant into the vagina up to the cervix and removed after 20 minutes. This was repeated in the second admission. The Softcup was quickly placed inside an open $50 \mathrm{ml}$ centrifuge tube and immediately placed into a box containing nitrogen. All cervicovaginal liquid samples were then transported to the laboratory for analysis.

\section{2. pH, Viscosity and Total Protein Measurements}

The $\mathrm{pH}$ was measured using a digital $\mathrm{pH}$ meter $(\Phi 11 \mathrm{pH}$ meter, Beckman Instruments Inc., Fullerton, CA, USA) and a glass microelectrode designed to measure $\mathrm{pH}$ in small volumes. The $\mathrm{pH}$ level was calibrated each time using standard buffer solutions (Sigma-AldtichpH 4.0, 7.0 and 10.0). The microelectrode was washed with deionized water and disinfected with a solution of benzalkonium chloride each time.

The viscosity of each sample was measured using the Cambridge MicroSample Viscometer (Cambridge Viscosity, Medford, MA, USA). The cervicovaginal liquid of all samples was centrifuged at $2000 \mathrm{~g}$ for 10 minutes at room temperature $\left(25^{\circ} \mathrm{C}\right)$, and the protein phase was removed for quantification. Finally, the samples were stored at $-70^{\circ} \mathrm{C}$ for future study.

\subsection{Isolation and Determination of Vaginal Microbiota}

Self-collected vaginal swabs from all subjects were treated according to the method described by Verstraelen et al. [11]. The swabs were incubated for 4 days at $37^{\circ} \mathrm{C}$ on a Schaedler agar enriched with $5 \%$ sheep blood, vitamin $\mathrm{K}$, haemin and sodium pyruvate. The isolates were then selected for identification. DNA was extracted through simple alkaline lysis before at DNA-PCR and capillary electrophoresis were performed as. The results were analyzed, and the microbiome composition in each sample was determined by comparing the tDNA-PCR fingerprint obtained from each isolate with a library of tDNA-PCR fingerprints. The presence, absence and prevalence of bacterial species/genera were assessed. Correlations between the microbiome composition and infertility were analyzed.

\subsection{Statistical Analysis}

We used GraphPad prism version 5 for the statistical analysis. Statistical comparisons were made using a two-tailed independent sample t-test. All values are presented as the mean $\pm \mathrm{SD}$. Significance was assumed when $p<0.05$. 


\section{Results}

\subsection{Demographic Characteristics of the Studied Women}

The ages of the infertile women group (mean 25.27 years) were not significantly different ( $p=0.42$ ) compared to control women (mean 27.95 years). The mean weight of the normal women was higher (mean $67.86 \mathrm{~kg}$ ) than that of the infertile women (mean $66.93 \mathrm{~kg}$ ), but the difference was not significant $(p=0.73)$, Figure 1. The mean height of women from normal group $(162.8 \mathrm{~cm})$ is higher than that of infertile women $(160.8 \mathrm{~cm})$ whereas their BMI is lower $(25.65 \mathrm{~kg} / \mathrm{m})$ than that of infertile women $(26.05 \mathrm{~kg} / \mathrm{m})$. However, the differences for both parameters are not significant $(p=0.747$ and 0.741 , respectively).

\subsection{The pH level of the Cervicovaginal Liquid}

The $\mathrm{pH}$ levels of 36 Cervicovaginal samples were measured (22 normal women and 14 infertile women). The present study demonstrated that the mean vaginal $\mathrm{pH}$ levels in normal women and infertile women were 3.96 and 5.06, respectively, and the difference between the two cohorts was statistically significant $(p<$ $0.0001)$. For normal women, the lowest $\mathrm{pH}$ value was 3.2 , and the highest was 5.1 whereas for the infertile women, the lowest $\mathrm{pH}$ value was 3.9, and the highest was 5.8 (Figure 2).

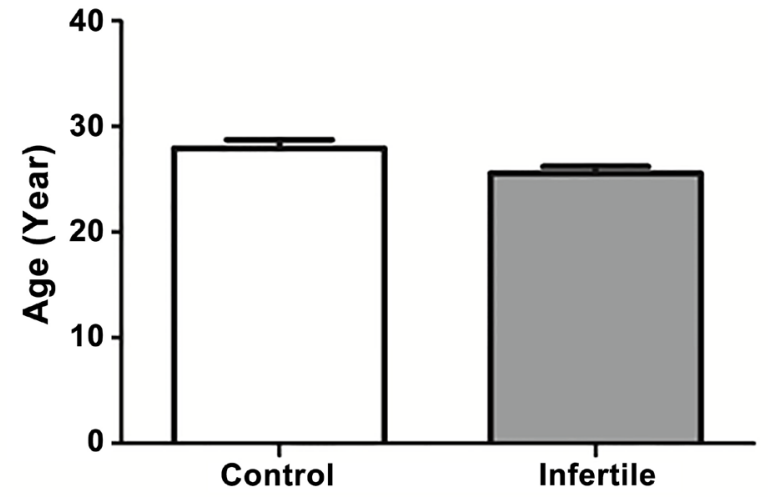

(a)

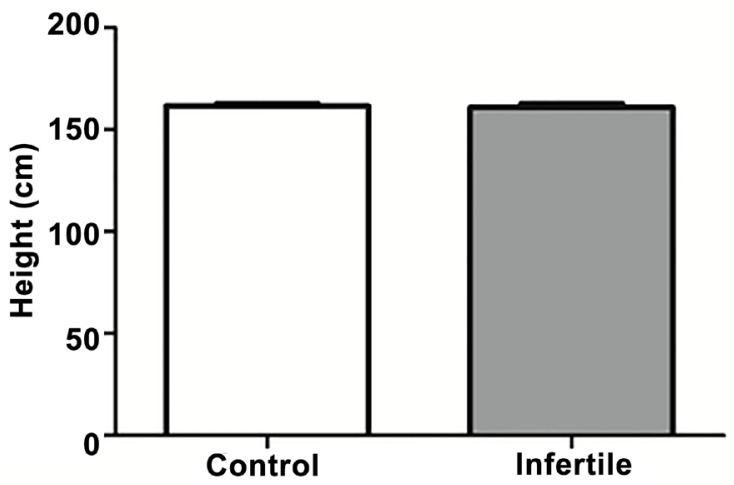

(c)

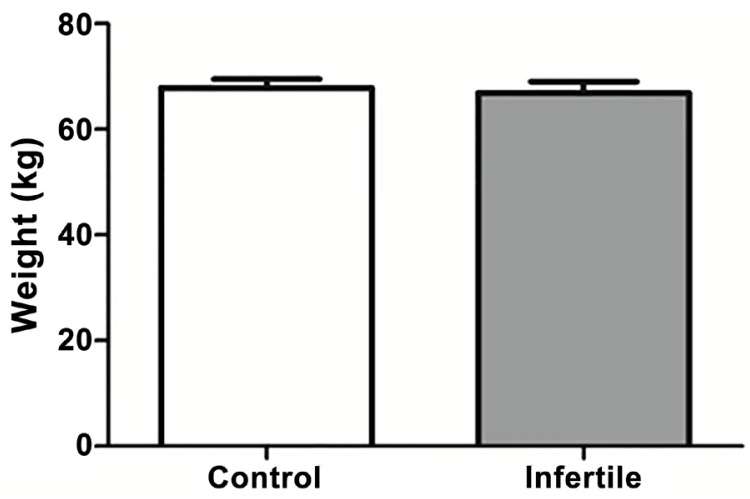

(b)

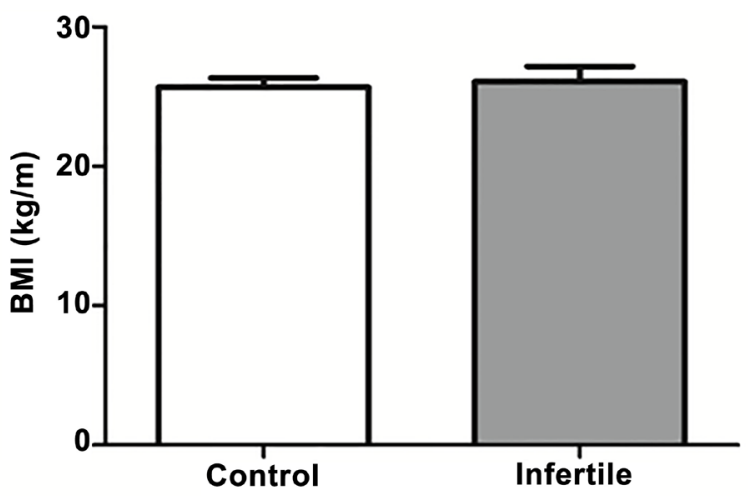

(d)

Figure 1. The mean values of age (a), body weight (b), height (c) and body mass Index (d) in the two studied groups of normal women compared to the infertile women. 


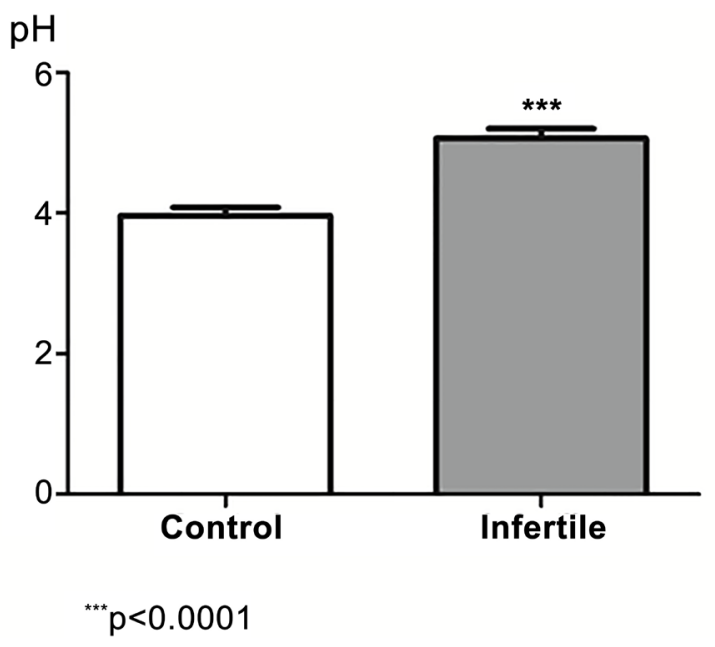

Figure 2. The mean $\mathrm{pH}$ values in the two studied groups of normal women compared to the infertile women.

The $\mathrm{pH}$ results show a clear correlation between the $\mathrm{pH}$ value and the floral species detected in the cervicovaginal liquid (Figure 3). In fact, normal flora, primarily composed of Lactobacillus species (i.e., L. gasseri L., crispatus, L. iners, $L$. vaginalis, L. jensenii, L. buchneri, L. cellobiosus, and L. fermentum) were detected at $\mathrm{pH}$ ranges from 3 to 4.5 (with the exception of one patient). Another subgroup of bacteria, primarily composed of Gardnerella vaginalis, Peptostreptococcus anaerobius and L. iners, was detected in a $\mathrm{pH}$ range between 4.5 and 5.5. The last subgroup, $\mathrm{pH}$ range $>5.5$, was mainly composed of Gardnerella vaginalis, Peptostreptococcus anaerobius, Mycoplasma hominis, Mobiluncus species and Atopobiumvaginae.

\subsection{Total Protein in the Cervicovaginal Liquid (mg)}

The protein content of the cervicovaginal liquid was significantly higher in the normal women compared to the infertile women $(p<0.0001)$ (Figure 4$)$. The mean value was 26.36 for the normal women and 20.27 for the infertile women.

\subsection{Viscosity of Cervicovaginal (Centipoise)}

Normal women were found to have higher cervicovaginal viscosities (mean value 1.56) compared to women who were determined to be infertile (mean value 1.10). This difference was significant $(p<0.0001)$ (Figure 5).

\section{Discussion}

Female infertility may be caused by many factors, including polycystic ovary syndrome, endometriosis, and fallopian tube problems. Many other factors could cause infertility in women. The physical properties of the cervicovaginal liquid must have an adequate consistency and a $\mathrm{pH}$ value for suitable proliferation of lactobacillus bacteria.

What attracted our attention in this study is the fact that in the second subgroup, L. iners (normal flora beneficial for vaginal health) coexisted with a 


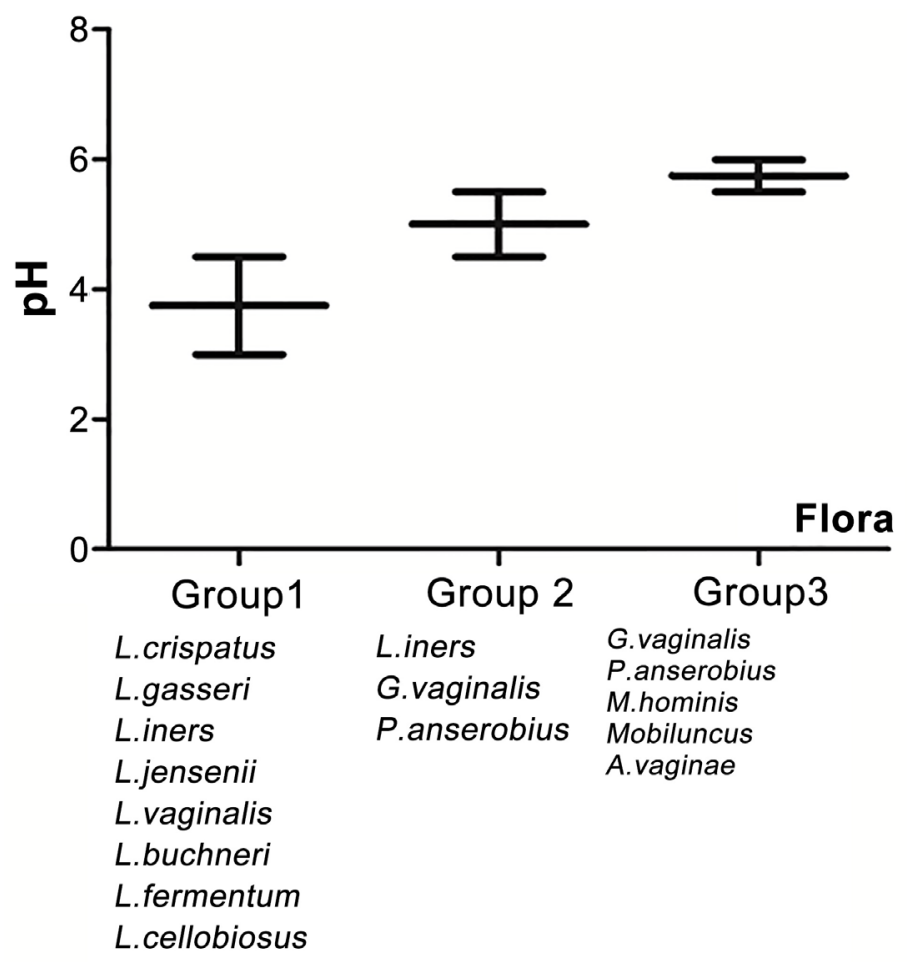

Figure 3. Relationship between the cervicovaginal $\mathrm{pH}$ values and the species of cervicovaginal bacterial flora. We determined 3 bacteria groups based on $\mathrm{pH}$ values: group 1 includes bacteria living at cervicovaginal acidic $\mathrm{pH}$ levels (from 3 to 4.5), group 2 includes bacteria living at $\mathrm{pH}$ levels 4.5 - 5.5, and group 3 includes bacteria living at $\mathrm{pH}$ levels $>5.5$.

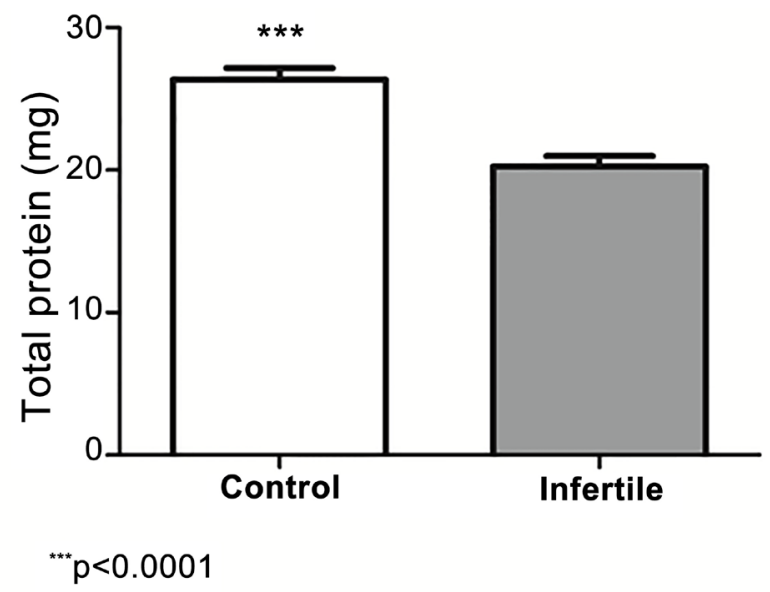

Figure 4. Total protein in the cervicovaginal mucus of the two studied groups of normal women compared to infertile women.

second type of harmful bacteria represented by Gardnerella vaginalis and Peptostreptococcus anaerobius. Our findings align with those of Jakobsson and Forsum [12] who have suggested that $L$. iners is a dominant part of the cervicovaginal flora when the flora is in a transitional stage between abnormal and normal. Moreover, Gardnerella vaginalis and Peptostreptococcus anaerobius have been reported to be the most acid resistant of the harmful species [7], which may 


\section{Viscosity}

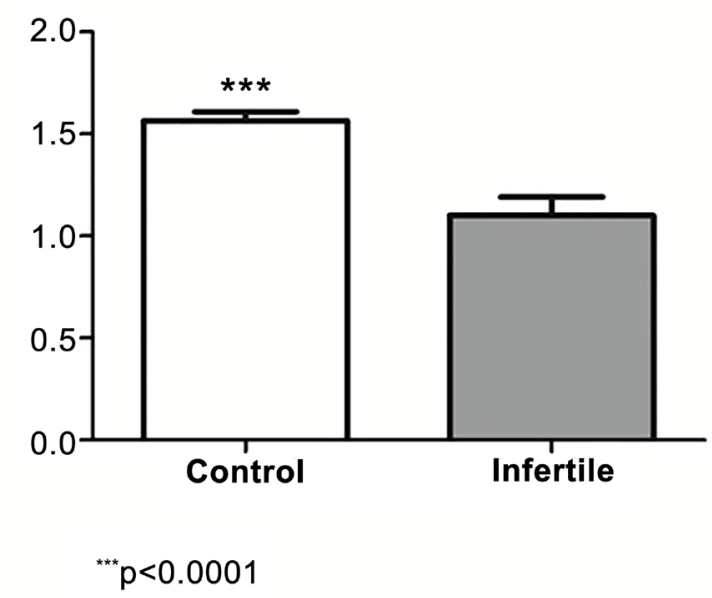

Figure 5. Viscositiesof the cervicovaginal mucus in the two studied groups of normal women compared to infertile women.

explain their presence in the $\mathrm{pH}$ range of 4.5 to 5 . Even $G$. vaginalis is not currently considered to be harmful because this species has been reported to be present in women without any symptoms [13]. In fact, a healthy vaginal $\mathrm{pH}$ is somewhere between 3.5 and 4.5 (slightly acidic) for most of the menstrual cycle, and it is generally self-regulating [14] [15]. This particular physical property of the cervicovaginal liquid represents the ideal environment for acidophilus bacilli, whereas the pathogenic saprophytes do not find the conditions favorable to proliferate [16]. A normal properly estrogenized vagina is characterized by a predominance of Lactobacillus species, such as L. crispatus, L. gasseri, L. iners, $L$. jensenii, L. vaginalis, and L. buchneri [13] [17]. Indeed, the glycogen is deposited in the epithelial cells of the vagina, which allows the proliferation of lactobacilli and the breakdown of this cellular glycogen. As a result, large amounts of lactic acid (generated by glucose anaerobic fermentation) and hydrogen peroxide are produced to decrease the vaginal $\mathrm{pH}$ level to the range of 3.5 - 4.5 [14] [15]. The latter provides a natural barrier to infections and prevents the uncontrolled growth of other bacteria present in the vagina. Moreover, this characteristic is thought to protect against sexually transmitted infection [14].

However, during ovulation and under the effect of ovarian hormones (primarily LH), an increase in cervical mucus causes $\mathrm{pH}$ to move more alkaline (7 14), which allows sperm to travel through the vagina and cervix into the fallopian tubes for fertilization. Many other factors may also cause the vaginal alkalization, such as long menstrual periods, inadequate douches and the use of broad-spectrum antibiotics [16]. These factors allow the decrease of the glucose metabolism by acidophilus bacilli, and, therefore, the decrease of lactic acid production, which represents an adequate environment to the proliferation of harmless and pathogenic vaginal microorganisms, such as Escherichia coli, Bacteroides fragilis, Mobiluncus spp., Neisseria gonorrhoeae, Gardnerella vaginalis, Peptostreptococcus anaerobius and Staphylococcus aureus [16]. We suggest that 
this environment may be one cause of infertility in the second cohort of women studied. In fact, many studies have demonstrated that an elevated vaginal $\mathrm{pH}$ level $(>5)$ correlates with recovering potentially pathogenic bacteria from the vagina [13]. Moreover, some studies have reported that an elevated $\mathrm{pH}$ greater than 4.5 increased the risk of preterm delivery of low-birth-weight infants [13] [18].

The differences in the protein quantity in the cervicovaginal liquid between the two groups suggest that the vaginal environments of the patients in the two groups are different and may be the cause of infertility. Chappell et al. [14] have reported that the protein content of cervicovaginal liquid was significantly lower in postmenopausal women compared to that of premenopausal women, which aligns with our results. Moreover, decreased protein levels in the cervicovaginal liquid could indicate a decreased amount of mucus and a decreased quantity of antimicrobial proteins, such as albumin and globulins, in the vaginal mucus [19].

Cervical mucus is considered to be a hydrogel that is composed of a highmolecular-weight component (gel phase) and a low-molecular-weight component (cervical plasma) [15]. Cervical mucus abnormalities can result in infertility (approximately 3\% of couples are facing infertility due to cervical mucus problems in females). In fact, alterations in the cervicovaginal mucus can affect its composition, which is generally associated with cervicitis [15] and acute inflammatory conditions. Therefore, the secreted mucus will be of low viscosity but with high leukocyte content. This physical feature of the mucus (viscosity) forms an environment that is not adequate for sperm to swim easily in, and it is even unable to maintain sperm vitality, which may be a cause of infertility.

\section{Acknowledgements}

The authors gratefully acknowledge the financial support provided by King Abdulaziz City for Science and Technology (S.F.306-35).

\section{References}

[1] Chang, S.H., Cheng, B.H., Lee, S.L., Chuang, H.Y., Yang, C.Y., Sung, F.C. and Wu, T.N. (2006) Low Blood Lead Concentration in Association with Infertility in Women. Environmental Research, 101, 380-386.

[2] Hruska, K.S., Furth, P.A., Seifer, D.B., Sharara, F.I. and Flaws, J.A. (2000) Environmental Factors in Infertility. Clinical Obstetrics and Gynecology, 43, 821-829. https://www.ncbi.nlm.nih.gov/pubmed/11100299

[3] Cribby, S., Taylor, M. and Reid, G. (2008) Vaginal Microbiota and the Use of Probiotics. Interdisciplinary Perspectives on Infectious Diseases, 2008, Article ID: 256490.

[4] van de Wijgert, J.H.H.M., Borgdorff, H., Verhelst, R., Crucitti, T., Francis, S. and Verstraelen, H. (2014) The Vaginal Microbiota: What Have We Learned after a Decade of Molecular Characterization? PLoS ONE, 9, e105998.

https://doi.org/10.1371/journal.pone.0105998

[5] Ravel, J., Gajer, P., Abdo, Z., Schneider, G.M., Koenig, S.S., McCulle, S.L., et al. 
(2011) Vaginal Microbiome of Reproductive-Age Women. Proceedings of the National Academy of Sciences of the United States of America, 108, 4680-4687. https://doi.org/10.1073/pnas.1002611107

[6] Fettweis, J.M., Serrano, M.G., Girerd, P.H., Jefferson, K.K. and Buck, G.A. (2012) A New Era of the Vaginal Microbiome: Advances Using Next-Generation Sequencing. Chemistry \& Biodiversity, 9, 965-976. https://doi.org/10.1002/cbdv.201100359

[7] Boskey, E.R., Telsch, K.M., Whaley, K.J., Moench, T.R. and Cone, R.A. (1999) Acid Production by Vaginal Flora in Vitro Is Consistent with the Rate and Extent of Vaginal Acidification. Infection and Immunity, 67, 5170-5175. http://iai.asm.org/content/67/10/5170.long\#sec-1

[8] Boskey, E.R., Cone, R.A., Whaley, K.J. and Moench, T.R. (2001) Origins of Vaginal Acidity: High D/L Lactate Ratio Is Consistent with Bacteria Being the Primary Source. Human Reproduction, 16, 1809-1813.

https://www.ncbi.nlm.nih.gov/pubmed/11527880 https://doi.org/10.1093/humrep/16.9.1809

[9] Kaewsrichan, J., Peeyananjarassri, K. and Kongprasertkit, J. (2006) Selection and Identification of Anaerobic Lactobacilli Producing Inhibitory Compounds against Vaginal Pathogens. FEMS Immunology and Medical Microbiology, 48, 75-83. https://doi.org/10.1111/j.1574-695X.2006.00124.x

[10] Voravuthikunchai, S.P., Bilasoi, S. and Supamala, O. (2006) Antagonistic Activity against Pathogenic Bacteria by Human Vaginal Lactobacilli. Anaerobe, 12, 221-226.

[11] Verstraelen, H., Verhelst, R., Claeys, G., et al. (2009) Longitudinal Analysis of the Vaginal Microflora in Pregnancy Suggests That L. crispatus Promotes the Stability of the Normal Vaginal Microflora and That L. gasseri and/or L. iners Are More Conducive to the Occurrence of Abnormal Vaginal Microflora. BMC Microbiology, 9, 116. https://doi.org/10.1186/1471-2180-9-116

[12] Jakobsson, T. and Forsum, U. (2007) Lactobacillus iners: A Marker of Changes in the Vaginal Flora? Journal of Clinical Microbiology, 45, 3145. https://doi.org/10.1128/JCM.00558-07

[13] Caillouette, J.C., Sharp, C.F., Zimmerman, G.J. and Roy, S. (1997) Vaginal pH as a Marker for Bacterial Pathogens and Menopausal Status. American Journal of $\mathrm{Ob}$ stetrics and Gynecology, 176, 1270-1275. https://doi.org/10.1016/S0002-9378(97)70345-4

[14] Chappell, C.A., Rohan, L.C., Moncla, B.J., Wang, L., Meyn, L.A., Bunge, K. and Hillier, S.L. (2014) The Effects of Reproductive Hormones on the Physical Properties of Cervicovaginal Fluid. American Journal of Obstetrics and Gynecology, 211, 226.e1226.e7. https://doi.org/10.1016/j.ajog.2014.03.041

[15] Nakano, F., Leão, B. and Esteves, E. (2015) Insights into the Role of Cervical Mucus and Vaginal $\mathrm{pH}$ in Unexplained Infertility. Medical Express, 2, M150207. https://doi.org/10.5935/medicalexpress.2015.02.07

[16] Haya, J., García, A., López-Manzanara, C., Balawi, M. and Haya, L. (2014) Importance of Lactic Acid in Maintaining Vaginal Health: A Review of Vaginitis and Vaginosis Etiopathogenic Bases and a Proposal for a New Treatment. Open Journal of Obstetrics and Gynecology, 4, 787-799. https://doi.org/10.4236/ojog.2014.413109

[17] Pendharkar, S., Magopane, T., Larsson, P.G., de Bruyn, G., Gray, G.E., Hammarström, L. and Marcotte, H. (2013) Identification and Characterisation of Vaginal Lactobacilli from South African Women. BMC Infectious Diseases, 13, 43. https://doi.org/10.1186/1471-2334-13-43

[18] Hemalatha, R., Ramalaxmi, B., Swetha, E., Balakrishna, N. and Mastromarino, P. (2013) Evaluation of Vaginal $\mathrm{pH}$ for Detection of Bacterial Vaginosis. The Indian 
Journal of Medical Research, 138, 354-359.

https://www.ncbi.nlm.nih.gov/pmc/articles/PMC3818598/

[19] Sharif, K. and Olufowobi, O. (2006) The Structure, Chemistry and Physics of Human Cervical Mucus. In: Jordan, J.A. and Singer, A., Eds., The Cervix, Blackwell Publishing Ltd., Oxford, 157-168. https://doi.org/10.1002/9781444312744.ch11

Submit or recommend next manuscript to SCIRP and we will provide best service for you:

Accepting pre-submission inquiries through Email, Facebook, LinkedIn, Twitter, etc. A wide selection of journals (inclusive of 9 subjects, more than 200 journals) Providing 24-hour high-quality service User-friendly online submission system Fair and swift peer-review system Efficient typesetting and proofreading procedure Display of the result of downloads and visits, as well as the number of cited articles Maximum dissemination of your research work

Submit your manuscript at: http://papersubmission.scirp.org/

Or contact arsci@scirp.org 